\title{
PENGARUH PENDIDIKAN KESEHATAN TERHADAP PENGETAHUAN MASYARAKAT TENTANG HIPERTENSI DI DESA BUKIT HARAPAN KABUPATEN BULUKUMBA
}

\author{
Hamdana \\ STIKES Panrita Husada Bulukumba \\ Alamat korespondensi : (hamdanadhana9@gmail.com/085242592250)
}

\begin{abstract}
ABSTRAK
Berdasarkan data Dinas Kesehatan Provinsi Sulsel (2015) dari 24 kabupaten atau kota dengan jumlah puskesmas 440 di Sulawesi Selatan jumlah kasus hipertensi yang didapatkan melalui pengukuran tekanan darah pada umur $>18$ tahun sebanyak 28,1\%.Sedangkan di Kab. Bulukumba kasus hipertensi urutan ke kedua tertinggi setelah Kab. Enrekang dengan jumlah kasus hipertensi sebanyak 30,8\%. Tujuan Penelitian ini adalah untuk mengetahui Pengaruh pendidikan kesehatan terhadap pengetahuan penderita hipertensi di desa Bukit Harapan Kabupaten Bulukumba. Desain penelitian yang digunakan dalam penelitian ini adalah jenis penelitian kuantitatif. Desain penelitian menggunakan pre-eksperimen dengan rancangan "one group pre-post test design". Sampel penelitian sebanyak 20 responden yang diambil dengan tehnik consecutive sampling. Analisis data pada penelitin ini menggunakan uji McNemar. Dengan menggunakan uji McNemar dengan tingkat kepercayaan $(\alpha: 0,05)$ berdasarkan hasil uji tersebut, didapatkan nilai $p: 0,00$. Dengan demikian $p$ : $0,00<(\alpha: 0,05)$. Maka hipotesis awal penelitian diterima dengan kesimpulan ada pengaruh pemberian pendidikan kesehatan terhadap pengetahuan masyarakat tentang hipertensi di Desa Bukit Harapan Kabupaten Bulukumba
\end{abstract}

\section{Kata Kunci: Hipertensi, Pendidikan kesehatan}

\section{PENDAHULUAN}

Hipertensi atau tekanan darah tinggi adalah suatu keadaan dimana seseorang mengalami tekanan darah diatas normal (Muttaqin, 2012). Menurut WHO (2013) dan JNC7 (2015) menjelaskan bahwa seseorang di katakan hipertensi apabila tekanan sistolik $\geq 140 \mathrm{mmHg}$, sedangkan tekanan diastolik $\geq 90 \mathrm{mmHg}$, dengan bertambahnya usia hampir semua orang mengalami peningkatan tekanan darah.

Berdasarkan data WHO (2015) mengatakan bahwa hipertensi adalah salah satu penyebab utama kematian dini di seluruh dunia dan hipertensi membunuh hampir 8 miliar orang setiap tahun didunia. Sekitar 1,56 miliar orang dewasa akan menderita hipertensi dan hampir 1,5 juta orang setiap tahun di kawasan Asia Selatan, dan diwilayah Asia Tenggara termasuk Indonesia insiden kasus hipertensi juga meningkat sebanyak $28 \%$.

Menurut Riskesdas (2013) prevalensi hipertensi di Indonesia yang didapatkan melalui pengukuran tekanan darah pada umur $\geq 18$ tahun sebesar $26,5 \%$. Survei Indikator Kesehatan Nasional tahun 2016 menunjukkan prevalensi meningkat menjadi $32,4 \%$. Dan didapatkan angka kejadian hipertensi pada obesitas $13,5 \%$ angka ini akan meningkat seiring dengan peningkatan indeks massa tubuh (Kemenkes, Detik Health, 2015)
Berdasarkan data Dinas Kesehatan Provinsi Sulsel (2015) dari 24 kabupaten atau kota dengan jumlah puskesmas 440 di Sulawesi Selatan jumlah kasus hipertensi yang didapatkan melalui pengukuran tekanan darah pada umur $>18$ tahun sebanyak $28,1 \%$.Sedangkan di Kab. Bulukumba kasus hipertensi urutan ke kedua tertinggi setelah Kab. Enrekang dengan jumlah kasus hipertensi sebanyak $30,8 \%$.

Badan pencegahan dan pengendalian penyakit di Kabupaten Bulukumba mencatat jumlah kasus hipertensi pada tahun 2016 sebanyak 10.430 jiwa, dengan jumlah laki-laki sebanyak 3.828 jiwa, sedangkan jumlah perempuan sebanyak 6.602.Angka ini menunjukkan peningkatan dari tahun sebelumnya yang tercatat di tahun 2014 sebanyak 6.355 jiwa. Sedangkan jumlah kasus obesitas di tahun 2016 sebanyak 913 jiwa,dengan jumlah laki-laki sebanyak 115 jiwa dan jumlah perempuan sebanyak 798 jiwa (Dinkes Bulukumba, 2015).

Berdasarkan data dari wilayah kerja puskesmas Bukit harapan tahun 2015 terdapat jumlah kasus hipertensi sebanyak 86 jiwa. Sedangkan hasil survei awal yang telah dilakukan oleh peneliti secara langsung di Desa Bukit Harapan, dengan jumlah penduduk di tahun 2015 sebanyak 1599 jiwa. Dengan jumlah Laki-laki sebanyak 813 jiwa, 
sedangkan perempuan sebanyak 786 jiwa di Kabupaten Bulukumba.

Hasil survei awal yang telah dilakukan oleh peneliti secara langsung di Desa Bukit Harapan, ditemukan penderita Hipertensi sebanyak 86 orang. Untuk itu perlunya upaya penurunan angka kejadian hipertensi pada masyarakat melalui pendidikan kesehatan dan penyadaran masyarakat untuk selalu berperilaku hidup sehat. Sehingga masyarakat menyadari bahwa kejadian hipertensi dapat menimbulkan sroke dan kematian. Jika hipertensi ini terjadi secara berkepanjangan, maka akan meningkatkan resiko bukan hanya stroke, Namun juga serangan jantung, gagal jantung dan gagal ginjal kronis.

Berdasarkan uraian masalah diatas, maka dapat di rumuskan masalah sebagai berikut: "Bagaimana pengaruh pendidikan kesehatan terhadap pengetahuan penderita hipertensi di desa Bukit Harapan?"

\section{BAHAN DAN METODE}

\section{Lokasi, Populasi, Sampel}

Penelitian ini dilaksanakan di Desa

Bukit Harapan Kabupaten Bulukumba pada bulan Agustus - Desember 2018. Populasi dalam penelitian ini adalah seluruh masyarakat yang ada di desa Bukit Harapan. dengan jumlah sampel pada penelitian ini adalah 68 orang.

1. Kriteria inklusi

Menurut Nursalam dan Pariani 2001dalam (Setiadi, 2013) adalah karakteristik umum subjek penelitin dari suatu populasi target dan terjangkau yang akan diteliti.
a. Penderita Hipertensi
b. Memungkinkan dalam mengikuti penelitian
c. Bersedia menjadi responden.

2. Kriteria Eklusi
Menurut Nursalam dan Pariani 2001dalam (Setiadi, 2013) adalah menghilangkan /mengeluarkan subjek yang memenuhi kriteria inklusi dan studi karena berbagai sebab.
a. Tidak sedang menderita komplikasi hipertensi
b. Tidak bersedia menjadi responden.

\section{Pengumpulan Data}

1. Data primer: Data primer adalah data yang diperoleh langsung dari responden yaitu dari hasil pengukuran tekanan darah denganmenggunakan tensi meter (Saryono, 2011).

2. Data sekunder: Data sekunder adalah data yang diperoleh dari pihak lain, tidak langsung diperoleh oleh peneliti dari subyek penelitian (Saryono, 2011). Data sekunder dalam penelitian ini adalah data yang diperoleh dari Puskesmas kecamatan Kabupaten Bulukumba.

\section{Pengolahan Data}

Menurut Saryono (2011) langkahlangkah dalam memproses data yaitu:

1. Editing

Data yang terkumpul selanjutnya disusun. Editing adalah memeriksa daftar pertanyaan yang telah diserahkan oleh para pengumpul data. Tujuannya adalah mengurangi kesalahan atau kekurangan yang ada di daftar pertanyaan.

2. Coding

Coding adalah mengklasifikasikan jawaban dari para responden kedalam kategori. Klasifikasi data merupakan usaha untuk menggolongkan, mengelompokkan dan memilah data berdasarkan klasifikasi tertentu. Kegiatan ini akan memudahkan dalam menguji hipotesis.

3. Tabulating

Tabulating adalah pekerjaan membuat tabel. Jawaban-jawaban yang telah diberi kode kemudian dimasukkan ke dalam tabel. Langkah terakhir dari penelitian ini adalah melakukan analisa data. Selanjutnya data dimasukkan ke komputer dan dianalisis secara statistik.

\section{Analisis Data}

Analisis data dilakukan untuk menjawab hipotesis penelitian. Untuk alasan tersebut dipergunakan uji statistik yang cocok dengan variabel penelitian. Analisis data dalam penelitian ini dilakukan melalui:

1. Analisis univariat

Analisis univariat disajikan untuk mendeskripsikan variabel bebas dan variabel terikat dengan menggunakan tabel distribusi yang konfirmasinya dalam bentuk presentase (Arikunto, S, 2010). Pada penelitian ini akan diketahui distribusi frekuensi mengenaikarakteristik responden, yaitu pengambilan data responden melalui kuesioner.

2. Analisis Bivariat

Analisa bivariat dilakukan untuk mengetahui hubungan antara tekanan darah sebelum dilakukan pendidikan kesehatan tentang hipertensi dengan tekanan darah setelah dilakukan pendidikan kesehatan tentang hipertensi. Uji statistik yang digunakan adalah uji Chi Squere jika memenuhi syarat tetapi jika tidak dari memenuhi digunakan uji Mc.Nemar. Uji ini bertujuan untuk melihat ada atau tidaknya perbedaan proporsi yang 
bermakna antara distribusi frekuensi yang di amati dengan di harapkan dengan derajat kemaknaan 0,05.

\section{HASIL PENELITIAN}

1. Karakteristik responden

Tabel 1 Distribusi karakteristik responden Di Desa Bukit Harapan Kab Bulukumba 2018. $(n=68)$

\begin{tabular}{|l|c|c|}
\hline Karakteristik & $\mathrm{n}$ & $\%$ \\
\hline Usia & & \\
30-34 tahun & 15 & 22 \\
35-39 tahun & 14 & 20,5 \\
40-44 tahun & 24 & 19,2 \\
$45-49$ tahun & 7 & 10,3 \\
$50-54$ tahun & 5 & 7,9 \\
55-59 tahun & 0 & 0 \\
60-64 tahun & 3 & 4,4 \\
\hline Jenis kelamin & & \\
Laki-Laki & 7 & 10,3 \\
Perempuan & 61 & 89,7 \\
\hline
\end{tabular}

Tabel 1 menunjukkan dari 68 respon terdapat tujuh kelompok umur, kelompok umur yang tertinggi adalah 40-44 tahun yaitu sebanyak $24(19,2 \%)$ responden dan yang terendah adalah 60-64 tahun sebanyak 3 responden (4,4\%). Untuk jenis kelamin kelompok tertinggi adalah perempuan yaitu 61 responden $(89,7 \%)$ dan untuk kelompok laki-laki 7 responden $(10,3 \%)$.

2. Analisis Univariat

Tabel 2 Distribusi tingkat pendidikan sebelum pemberian pendidikan kesehatan kepada masyarakat tentang hipertensi di Desa Bukti Harapan Kab. Bulukumba 2018.

\begin{tabular}{|l|c|c|}
\hline Pengetahuan & $\mathrm{n}$ & $\%$ \\
\hline Baik & 38 & 55,9 \\
\hline Kurang & 30 & 44,1 \\
\hline Total & 68 & 100 \\
\hline
\end{tabular}

Pada Tabel 2 menjelaskan tingkat pengetahuan masyarakat sebelum dilakukan pendidikan kesehatan di Desa Bukit harapan Kabupaten Bulukumba 2018, masyarakat yang memiliki tingkat pengetahuan baik sebanyak 38 responden $(55,9 \%)$ dan untuk tingkat pengetahuan kurang sebanyak 30 responden $(44,1 \%)$.

Tabel 3 Distribusi tingkat pendidikan setelah pemberian pendidikan kesehatan kepada masyarakat tentang hipertensi di Desa Bukti Harapan Kab. Bulukumba 2018

\begin{tabular}{|c|c|c|}
\hline Pengetahuan & $\mathrm{n}$ & $\%$ \\
\hline Baik & 63 & 92,7 \\
\hline Kurang & 5 & 7,4 \\
\hline Total & 68 & 100 \\
\hline
\end{tabular}

Pada Tabel 3 menjelaskan tingkat pengetahuan masyarakat setelah dilakukan pendidikan kesehatan di Desa Bukit harapan Kabupaten Bulukumba 2018, masyarakat yang memiliki tingkat pengetahuan baik sebanyak 63 responden $(92,7 \%)$ dan untuk tingkat pengetahuan kurang sebanyak 5 responden $(7,4 \%)$.

\section{Analisis Bivariat}

Tabel 4 anlisis hubungan perubahan tingkat pengetahuan masyarakat setelah pemberian pendidikan kesehatan di Desa Bukit harapan kab. Bulukumba 2018

\begin{tabular}{|c|c|c|c|c|}
\hline \multirow{2}{*}{ Kategori } & \multicolumn{3}{|c|}{ Tingkat pengetahuan } \\
\cline { 2 - 5 } & \multicolumn{2}{|c|}{ Pretest } & \multicolumn{2}{c|}{ Post test } \\
\cline { 2 - 5 } & $\mathrm{n}$ & $\%$ & $\mathrm{n}$ & $\%$ \\
\hline Baik & 38 & 55,9 & 63 & 92,7 \\
\hline Kurang & 30 & 44,1 & 5 & 7,4 \\
\hline Total & 68 & 100 & 30 & 100 \\
\hline \multicolumn{5}{|c|}{$p=0,000$} \\
\hline
\end{tabular}

Berdasarkan tabel 4 diatas dari total 68 responden, menunjukkan bahwa nilai analisis pre-test pengetahuan dan post-test pengetahuan didapatkan nilai $p 0,000$ ( $\alpha$ 0,05 ), hal ini menunjukkan bahwa ada perbedaan proporsi sebelum dan setelah diberikan pendidikan kesehatan atau dengan kata lain ada pengaruh yang signifikan terhadap pemberian pendidikan kesehatan terhadap pengetahuan masyarakat tentang hipertensi di Desa Bukit harapan Kabupaten Bulukumba 2018.

\section{PEMBAHASAN}

Setelah diberikan pendidikan kesehatan tentang hipertensi terhadap 68 responden yang tinggal di Desa Bukit harapan Kabupaten Bulukumba, terjadi peningkatan jumlah masyarakat yang memiliki tingkat pengetahuan baik tentang hipertensi yang dapat dilihat dari nilai $p(0,000)$.

Hasil penelitian ini didukung oleh beberapa penelitian terdahulu, salah satu hasil penelitian mengatakan bahwa ada perbedaan yang signifikan antara sebelum dan setelah dilakukan penyuluhan kesehatan tentang hipertensi terhadap perawatan hipertensi pada penderita hipertensi usia 50-60 tahun pada kelompok eksperimen (Sulistianingsih, 2010).

Untuk hubungan antara pendidikan kesehatan dan perubahan pengetahuan responden telah dibuktikan oleh penelitian yang dilakukan oleh Susanti, Suryani dan Shobirun (2010), adapun hasil dari penelitian ini adalah didapatnya nilai $p(0,000)$ yang artinya terdapat pengaruh yang signifikan antara pemberian pendidikan kesehatan 
dengan perubahan pengetahuan. Hal tersebut sesuai juga dengan hasil penelitian yang dilakukan oleh Maharani, Chairuddin dan Sri Darmawan (2013) di Desa Patobong Kecamatan Mattiro Sompe Kabupaten Pinrang dengan hasil penelitian ada pengaruh penyuluhan kesehatan terhadap pengetahuan hipertensi masyarakat desa Patobong dengan nilai $p(0.0001)$.

Mekanisme adanya perbedaan pengetahuan secara bermakna ini disebabkan adanya faktor informasi dan komunikasi yang mempengaruhi pembentukan pengetahuan. Informasi yang diberikan langsung maupun tidak langsung mempunyai pengaruh dalam peningkatan pengetahuan, pembentukan opini dan kepercayaan orang. Di bidang kesehatan informasi dapat diperoleh melalui tatap muka langsung dengan penyampai informasi seperti pendidik, petugas kesehatan, tokoh masyarakat, tokoh agama serta aparat pemerintah yang mendukung serta dapat diperoleh melalui berbagai media massa seperti radio, televisi, majalah, surat kabar dll. Adanya informasi baru mengenai sesuatu hal akan memberikan landasan kognitif bagi terbentuknya sikap terhadap hal tersebut. Ragam pesan subjektif yang dibawa oleh informasi tersebut cukup kuat dan memberikan dasar afektif dalam menilai sesuatu hal sehingga terbentuklah pengetahuan baru (Bastable,2002).

Hasil penelitian ini mengungkapkan informasi yang diberikan tersampaikan dengan baik kepada masyarakat, sehingga terjadi peningkatan yang signifikan dari jumlah masyarakat yang tingkat pengetahuannya kurang ke tingkat pengetahuan baik tentang hipertensi.

\section{KESIMPULAN}

Berdasarkan tujuan khusus yang diungkapkan, maka dirumuskan kesimpulan sebagai berikut:

1. Sebelum dilakukan pendidikan kesehatan, jumlah responden dengan tingkat pengetahuan baik sebanyak 38 responden $(55,9 \%)$ dan tingkat pengetahuan kurang sebanyak 30 responden (44,1\%).

2. Setelah dilakukan pendidikan kesehatan jumlah responden dengan tingkat pengetahuan baik sebanyak 63 responden $(72,7 \%)$ dan tingkat pengetahhuan kurang sebanyak 5 responden $(7,4 \%)$.

3. Dengan menggunakan uji Mc Nemar didapatkan hasil nilai $p(0,000)$ sehingga dapat disimpulakan ada hubungan antara pemberian pendidikan kesehatan dengan perubahan pengetahuan masyarakat tentang hipertensi di Desa Bukit harapan kabupaten Bulukumba.

\section{SARAN}

1. Bagi petugas kesehatan untuk memberikan pendidikan kesehatan kepada masyarakat secara terprogram dan berkelanjutan.

2. Bagi peneliti selanjutnya dapat dijadikan acuan sebagai data-data dasar untuk meneliti faktor-faktor yang mempengaruhi pengetahuan masyarakat tentang hipertensi.

3. Bagi institusi pendidikan, dapat menjadikan pemberian pendidikan kesehatan sebagai salah satu aplikasi program pengabdian masyarakat.

\section{DAFTAR PUSTAKA}

Arikunto, S. (2010). Prosedur Penelitian Suatu Pendekatan Praktek. Rineka Cipta:Yogyakarta.

Bastable, B. S. (2002). Perawat sebagai pendidik prinsip-prinsip pengajaran dan pembelajaran. Jakarta: EGC.

Dinas Kesehatan Provinsi Sulsel. (2015). Profil Kesehatan Provinsi Sul Sel. Sulawesi Selatan: Dinas Kesehatan Provinsi Sulawesi Selatan.

Dinkes Bulukumba. (2016). Seksi Pencegahan dan penanggulangan Penyakit.

Kemenkes. (2017, Mei Rabu). Detik Health. Retrieved Maret Senin, 2018, from Kemenkes Sebut kasus Hipertensi di Indonesia Terus Meningkat: http://m.detik.com

Maharani, Chairuddin, \& Darmawan, S. (2013). Pengaruh penyuluhan kesehatan terhadap pengetahuan masyarakat tentang penyakit hipertensi di desa Patobong Kecamatan mattiro Sompe Kabupaten Pinrang.

Mila, M., Anida, \& Ernawati, Y. (2016). Hubungan Aktifitas Fsik Dengan Tekanan Darah Pada lansia di Dusun Miri Desa Sriharjono Imogiri Bantul.

Muttaqin, A. (2012). Asuhan Keperawatan klien dengan gangguan sistem kardiovaskular. Jakarta: Salemba Medika.

Notoatmodjo, S. (2010). Metodologipenelitiankesehatan, RinekaCipta: Jakarta 
Nursalam, (2011). Metodologi Penelitian IImu Keperawatan Pendekatan Praktis. Salemba Medika: Jakarta

Nursalam. (2016). Meteodologi penelitian keperawatan pendekatan praktis, ed 4. Salemba Medika: Jakarta

Saryono. (2011). MetodologiPenelitianKesehatan.Jogjakarta

Sugiyono. (2012). Metodepenelitiankuantitaif, kualitatifdan R\&D. Alfabeta: Bandung

Sujarweni, W. (2014). Metodologi penelitian keperawatan. GAVA MEDIA: Yogyakarta.

Sulistianingsih, A. (2010). Pengaruh penyuluhan kesehatan hipertensi terhadap perawatan hipertensi pada penderita hipertensi usia 50-60 tahun di Nogosari Ukirsari Imogiri Bantul. Prodi Keperawatan Stikes Aisyiah Yogyakarta.

Susanti, M. T., Suryani, M., \& Shobirun. (2010). Pengaruh pendidikan kesehatan tentang hipertensi terhadap pengetahuan dan sikap mengelola hipertensi di Puskesmas Pandanaran Semarang.

Syamsuddin, Muriyati, Asnidar, Sumarni. (2015). Metodologi Penelitian Internal. CV.WADE GROUP: Ponorogo Indonesi 